\title{
Acidentes e violência na infância: evidências do inquérito sobre atendimentos de emergência por causas externas - Brasil, 2009
}

\author{
Accidents and violence in childhood: survey evidence \\ of emergency care for external causes - Brazil, 2009
}

\author{
Deborah Carvalho Malta ${ }^{1}$ \\ Márcio Dênis Medeiros Mascarenhas ${ }^{2}$ \\ Regina Tomie Ivata Bernal ${ }^{3}$ \\ Anna Paula Bise Viegas ${ }^{2}$ \\ Naiza Nayla Bandeira de Sá ${ }^{2}$ \\ Jarbas Barbosa da Silva Junior ${ }^{1}$
}

${ }^{1}$ Secretaria de Vigiläncia em Saúde, Ministério da Saúde. Esplanada dos Ministérios, Bloco G, Edifício Sede, $1^{\circ}$ andar, Sala 142. 70058-900 Brasília DF.

deborah.malta@saude.gov.br ${ }^{2}$ Coordenação Geral de Vigilância de Doenças e Agravos Não

Transmissíveis, Secretaria de Vigilância em Saúde,

Ministério da Saúde.

${ }^{3}$ Faculdade de Saúde

Pública, Universidade de São Paulo.

\begin{abstract}
Understanding the characteristics and magnitude of accidents and violence due to external causes in children from 0 to 9 years of age is becoming ever more important in Public Health. The scope of this paper was to analyze emergency care for accidents due to external causes in children. The Sentinel Urgency and Emergency Services of the Violence and Accident Vigilance System (VIVA Survey), performed in 74 urgency services in the Federal District and 23 State capitals in 2009 was used. Data of 7,123 children were analyzed: 6,897 (96.7\%) victims of accidents and 226 (3.3\%) of violence. In comparison with victims of violence, the visits for accidents were more frequent among white children from 2 to 5 years old occurring in the home $(p<0.05)$. Among the accidents, falls and burns predominated in the 0 to 1group, while traffic accidents were most frequent in the 6 to 9-year-old age group $(p<0.001)$. With respect to violence, the visits for neglect and physical assault predominated, respectively, in extreme age groups, with someone in the family being the perpetrator $(p<0.001)$. Information on the occurrence of external causes in children may support health promotion policies, besides guiding health professionals, teachers and families in the prevention of such causes.
\end{abstract}

Key words Childhood, Injuries, Survey, External causes, Emergency attendance, Violence
Resumo Compreender as características e a magnitude das causas externas (acidentes e violência) em crianças de 0 a 9 anos de idade torna-se cada vez mais importante em Saúde Pública. O objetivo do presente artigo foi analisar os atendimentos de emergência por causas externas em crianças. Utilizaram-se dados do Sistema de Vigilância de Violências e Acidentes em Serviços Sentinelas de Urgência e Emergência (Inquérito VIVA), realizado em 74 serviços de urgência do Distrito Federal e 23 capitais no ano 2009. Analisaram-se dados de 7.123 crianças: 6.897 (96,7\%) vítimas de acidentes e 226 $(3,3 \%)$ de violência. Em comparação às vítimas de violência, os atendimentos por acidentes foram mais frequentes entre crianças de 2 a 5 anos, de pele branca e ocorridos no domicílio ( $p<0,05$ ). Dentre os acidentes, as quedas e queimaduras predominaram no grupo de 0 a 1 ano, enquanto os acidentes de transporte foram mais frequentes no grupo de 6 a 9 anos ( $p<0,001)$. Quanto às violências, atendimentos por negligência e agressão física predominaram, respectivamente, nos grupos extremos de faixa etária, sendo um familiar identificado como agressor $(p<0,001)$. Informações sobre ocorrência de causas externas em crianças podem apoiar políticas de promoção da saúde, além de orientar profissionais de saúde, educadores e famílias na prevenção destas causas.

Palavras-chave Infância, Acidentes, Inquérito, Causas externas, Atendimento de emergência, Violência 


\section{Introdução}

Acidentes e violências compõem as chamadas causas externas, que representam o principal problema de mortalidade em crianças de 1 a 9 anos, tornando-se cada vez mais relevante em saúde pública compreender sua distribuição, as causas, as características, a magnitude e os aspectos relacionados à sua ocorrência. Globalmente, as maiores taxas de mortalidade por causas externas na infância encontram-se em países da África e Ásia e os menores valores na América do Norte e Europa ${ }^{1,2}$.

A Organização Mundial da Saúde (OMS) ${ }^{1}$ estima cerca de 950 mil mortes por causas externas entre crianças menores de 18 anos de idade a cada ano, e mais de 10 milhões de incapacidades. A maioria destes eventos são evitáveis e considerados não intencionais como: lesões no trânsito, afogamentos, queimaduras, quedas. As lesões intencionais, como a violência física, negligência e abusos sexuais, respondem por mais de 200 mil mortes por ano em jovens e crianças.

No Brasil, dados do Sistema de Informações sobre Mortalidade (SIM) ${ }^{2}$ apontam a ocorrência de 4.111 óbitos em crianças de 0 a 9 anos em 2009 (taxa de mortalidade de 12,6/100.000 habitantes dessa faixa etária). Destes óbitos, 1.129 correspondiam a acidentes de transporte, 318 a agressões ou homicídios, 162 a quedas e o restante a outros acidentes. Em 2010, foram registradas 89.650 internações hospitalares por causas externas na população de 0 a 9 anos em serviços financiados pelo Sistema Único de Saúde.

As lesões decorrentes de acidentes e violências afetam pessoas de todas as idades, mas entre crianças têm características especiais por resultarem em lesões sérias como déficits neurológicos persistentes, decorrentes de traumatismos cranianos, déficits motores em indivíduos que se encontram em plena fase de crescimento e desenvolvimento $^{3-5}$. Além disto, os traumas decorrentes das causas externas podem trazer danos emocionais e psicológicos que repercutirão ao longo de toda a vida das vítimas, acarretando consequências também para a família e sociedade ${ }^{1}$.

O tema da violência contra a criança tem sido cada vez mais objeto de estudos no país e no mundo ${ }^{1,2,6}$. $\mathrm{A} \mathrm{OMS}^{7}$ distingue quatro naturezas de violência contra a criança: abuso físico, sexual, emocional ou psicológico e negligência. Na maioria das vezes, esses eventos permanecem silenciados no interior das famílias, escolas, comunidade e serviços de saúde ${ }^{8}$. São descritas ainda violências praticadas contra crianças/adolescentes em situação de rua, crianças trabalhadoras, violência escolar, ou bullying, dentre outras formas ${ }^{9,10}$.

A violência contra as crianças geralmente envolve uma relação assimétrica e pode ocorrer em diferentes formatos e em diferentes grupos econômicos e sociais ${ }^{8,11}$. A violência familiar é muito frequente e invisível, sendo praticada dentro dos lares, por quem deveria proteger as crianças. A mesma de caracteriza por todo tipo de omissão que prejudique o bem estar, a integridade física, psicológica, a liberdade, ou direito de desenvolvimento de algum membro da família ${ }^{12}$.

A maioria dos estudos disponíveis no país se concentra em aspectos como morbidade hospitalar e mortalidade por acidentes e violências, abrangendo os eventos de maior gravidade (internação ou óbito) disponíveis no Sistema de Informações sobre Mortalidade (SIM) e no Sistema de Internações Hospitalares do Sistema Único de Saúde (SIH/SUS) 3,13-15.

Apesar da existência desses dois grandes sistemas de informação de abrangência nacional, o cenário dos eventos relativos às violências contra crianças no Brasil ainda é subdimensionado, o que requer o desenvolvimento de diferentes estratégias de investigação como estudos que analisem registros de denúncias aos conselhos tutelares e delegacias especializadas ${ }^{16-18}$ ou sobre casos atendidos em serviços especializados de atenção ás vítimas de violência ${ }^{19,20}$. Mesmo assim, nenhum deles é capaz de, isoladamente, descrever a totalidade da extensão do problema, especialmente no que se refere às lesões de menor gravidade e que correspondem à maior parcela das ocorrências.

Com o intuito de fornecer mais informações sobre esses eventos, o Ministério da Saúde implantou em 2006 o Sistema de Vigilância de Violências e Acidentes em Serviços Sentinelas de Urgência e Emergência (Inquérito VIVA), possibilitando analisar características epidemiológicas dos atendimentos de emergência por causas externas em serviços selecionados em alguns municípios, capitais de estado e Distrito Federal ${ }^{1-22}$. Tal estratégia de vigilância já foi realizada em três edições (nos anos 2006, 2007 e 2009, possibilitando analisar as características dos atendimentos às vítimas de causas externas atendidas em serviços de urgência e emergência da rede assistencial do Sistema Único de Saúde (SUS), sua distribuição, características da ocorrência, como local, horário, gravidade, características do agressor, dentre

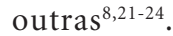

O estudo das causas e circunstâncias desses agravos junto à população infantil torna-se es- 
sencial para o desenvolvimento de estratégias de promoção à saúde e prevenção destes eventos.

O presente artigo tem por objetivo descrever os atendimentos de emergência por acidentes e violências em crianças atendidas em unidades de urgência e emergência segundo características demográficas, da ocorrência e do atendimento.

\section{Métodos}

Trata-se de estudo transversal, com dados coletados entre setembro e novembro de 2009, em 74 serviços de urgência e emergência localizados nas 23 capitais de Estado brasileiras e Distrito Federal, participantes do Inquérito VIVA 2009. Apenas três capitais não conseguiram executar o inquérito devido a razões técnico-operacionais ${ }^{24}$.

A população de estudo foi composta pelas vítimas de violências e acidentes (causas externas) que procuraram atendimento nos serviços de urgência e emergência no âmbito do Sistema Único de Saúde (SUS) nas capitais e Distrito Federal. Para a seleção dos estabelecimentos que compuseram a amostra, foi utilizado o Cadastro Nacional de Estabelecimentos de Saúde (CNES) para identificar os estabelecimentos habilitados para atendimento de urgência e emergência. Foram selecionados serviços de maior demanda e procura da população em cada capital, segundo os registros de internação no SIH/ SUS e de atendimentos nos Inquéritos VIVA 2006 e 2007 (para aqueles serviços participantes da pesquisa naqueles anos). Após a seleção dos estabelecimentos, procedeu-se à sua validação junto aos gestores de cada município, para conferir os serviços de maior demanda por atendimento.

Para a definição do tamanho da amostra, considerou-se o critério de precisão para as estimativas de prevalências fixadas para o estudo. Assim, assumindo coeficiente de variação inferior a $30 \%$ e o erro padrão menor que 3 , o tamanho da amostra foi de, no mínimo, 1.500 atendimentos por causas externas em cada uma das capitais.

O procedimento de sorteio utilizado foi a amostragem por conglomerado em único estágio, sendo o turno a unidade primária de amostragem (UPA). Todos os atendimentos por causas externas (violências e acidentes) do turno sorteado foram incluídos na amostra. Para efeito de sorteio de turnos, considerou-se o período de coleta de 30 dias dividido em dois turnos, totalizando 60 turnos, sendo 30 diurnos (7h00min às $18 \mathrm{~h} 59 \mathrm{~min})$ e 30 noturnos $(19 \mathrm{~h} 00 \mathrm{~min}$ às 6h59min). O número de turnos a ser sorteado em cada estabelecimento foi obtido pela razão entre o tamanho mínimo da amostra de atendimentos por causas externas e a média de atendimentos por causas externas realizados no mesmo estabelecimento em anos anteriores. Para garantir o tamanho mínimo da amostra, nas capitais, foram sorteados dois turnos reservas para cada serviço.

Visando a padronização da coleta foram realizados treinamentos pela equipe da Coordenação de Vigilância de Doenças e Agravos Não Transmissíveis da Secretaria de Vigilância em Saúde do Ministério da Saúde (CGDANT/SVS/MS) junto aos técnicos das secretarias estaduais e municipais de saúde envolvidas ${ }^{24}$. As entrevistas foram realizadas por acadêmicos dos cursos de Enfermagem e Medicina e por profissionais de saúde previamente treinados, sob supervisão de técnicos das secretarias de saúde. A cada paciente admitido no setor de emergência em decorrência de causas externas (violências e acidentes), os entrevistadores iniciavam a abordagem da vítima ou acompanhante (quando o paciente era menor ou encontrava-se impossibilitado de responder) para solicitar autorização e iniciar a entrevista ${ }^{24}$.

Os dados foram digitados no programa Epi Info 3.5.1, no Setor de Vigilância Epidemiológica de cada município participante da pesquisa e transferidos para o Ministério da Saúde via e-mail. Foi realizada a análise de consistência e identificação de duplicidade dos dados pela equipe técnica do Ministério da Saúde, utilizando o programa Link Plus, versão 2.0. As análises foram processadas no programa STATA versão 10.0, do qual se utilizou o módulo "svy", adequado para obtenção de estimativas dos parâmetros populacionais não viciadas quando os dados são provenientes de planos de amostragem complexos.

A presente análise inclui somente os atendimentos ocorridos entre crianças menores de 10 anos, desagregados por faixa etária ( 0 a 1 ano, 2 a 5 anos, 6 a 9 anos). Foram analisadas as seguintes variáveis: sexo, raça/cor da pele, meios de locomoção utilizados para chegar ao serviço de urgência, local de ocorrência, natureza da lesão, parte do corpo atingida, turno e dia de atendimento, evolução na emergência, tipo de evento e tipo de vítima. A hipótese nula de independência entre as variáveis qualitativas foi averiguada pelo teste do qui-quadrado com nível de significância de 5\%.

$\mathrm{O}$ projeto foi aprovado pela Comissão $\mathrm{Na}$ cional de Ética em Pesquisa (CONEP). Como os dados serão utilizados para fins de vigilância epidemiológica, a assinatura do termo de consenti- 
mento livre e esclarecido foi substituída por consentimento verbal, obtido pelo paciente ou por seu responsável. Foi garantido total anonimato e privacidade aos pacientes, profissionais e gestores dos serviços onde a pesquisa foi realizada, assim como a liberdade em desistir de participar da entrevista a qualquer momento, sem prejuízo de qualquer natureza para si próprio ou terceiros, atendendo às recomendações da Resolução $n^{\circ} .196 / 1996^{25}$.

\section{Resultados}

Foram analisadas informações referentes a 7.123 vítimas de causas externas com menos de 10 anos de idade atendidas nos serviços incluídos no Inquérito VIVA 2009, ou 17,9\% do total de atendimento realizados. Dos atendimentos em crianças, $6.897(96,8 \%)$ foram vítimas de acidentes e $226(3,2 \%)$, de violências.

A Figura 1 mostra que as capitais com maior frequência de atendimentos por quedas foram Belém (PA) e Fortaleza (CE) e, ocorrem em todas as cidades, em primeiro lugar, exceto em Campo Grande (MS) e Palmas (TO). Nestas últimas destacaram-se os atendimentos decorren- tes de outros acidentes (que englobam um grupo extenso de ocorrências como corpo estranho, afogamentos, choque contra objetos, outros). Os acidentes de transporte foram a terceira causa de demanda por atendimento de emergência, com maior frequência em Fortaleza (CE), Macapá (AP), Aracajú (SE), Rio Branco (AC) e Palmas (TO). As maiores porcentagens de atendimento por queimaduras foram observadas em Campo Grande (MS) e Curitiba (PR).

As características das crianças atendidas nos serviços sentinela, segundo o tipo de ocorrência, estão apresentadas na Tabela 1. Do total de crianças, $18,9 \%$ tinham até 1 ano de idade, $41,6 \%$ de 2 a 5 anos e 39,4\% de 6 a 9 anos; destaca-se a ocorrência de acidentes em crianças de 2 a 5 anos e de violências em crianças de 0 e 1 ano $(\mathrm{p}=0,0031)$. Os meninos predominaram em ambos os tipos de ocorrência. Quanto à raça/cor da pele, 62,8\% eram não brancos (negros, pardos, amarelos, indígenas), com maior porcentagem entre as vítimas de violência $(\mathrm{p}<0,001)$; a maioria das ocorrências $(66,6 \%)$ se deu no domicílio, sendo este local associado estatisticamente aos acidentes ( $p$ $=0,0234)$; os cortes foram a lesão mais frequente $(35,7 \%)$, seguidos de contusão. A cabeça e tronco $(52,1 \%)$ foram os segmentos corporais mais

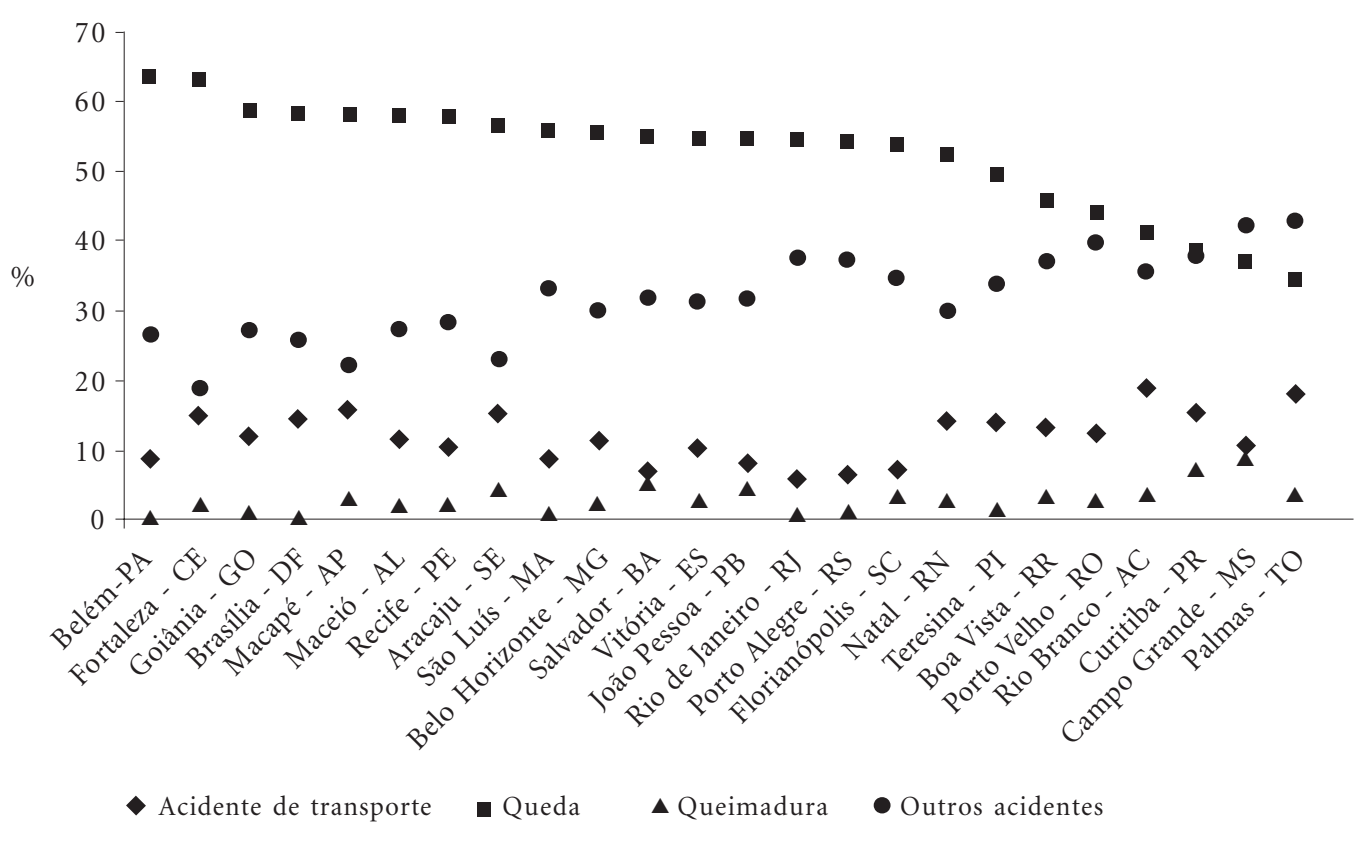

Figura 1. Distribuição percentual dos atendimentos de emergência por acidentes entre crianças segundo tipo de evento e município de notificação. 23 capitais e Distrito Federal, Brasil, 2009. 
Tabela 1. Características dos atendimentos de emergência por acidentes e violência entre crianças segundo tipo de ocorrência. 23 capitais e Distrito Federal, Brasil, 2009.

\begin{tabular}{|c|c|c|c|c|}
\hline Características & $\begin{array}{c}\text { Total }^{\mathrm{a}} \\
(\mathrm{n}=7.123) \\
\%\end{array}$ & $\begin{array}{c}\text { Acidentes }^{\mathrm{a}} \\
(\mathrm{n}=6.897) \\
\%\end{array}$ & $\begin{array}{c}\text { Violência }^{a} \\
(\mathbf{n}=226) \\
\%\end{array}$ & Valor de $\mathrm{p}^{\mathrm{b}}$ \\
\hline \multicolumn{5}{|l|}{ Faixa etária (anos) } \\
\hline 0 a 1 & 18,9 & 18,6 & 27,9 & \multirow[t]{3}{*}{0,0031} \\
\hline 2 a 5 & 41,6 & 42,0 & 31,9 & \\
\hline 6 a 9 & 39,4 & 39,4 & 40,2 & \\
\hline \multicolumn{5}{|l|}{ Sexo } \\
\hline Masculino & 59,6 & 59,4 & 64,7 & \multirow[t]{2}{*}{0,1397} \\
\hline Feminino & 40,4 & 40,6 & 35,3 & \\
\hline \multicolumn{5}{|l|}{ Raça/cor da pele } \\
\hline Branca & 37,2 & 37,7 & 22,1 & \multirow[t]{2}{*}{0,0000} \\
\hline Não branca & 62,8 & 62,3 & 77,9 & \\
\hline \multicolumn{5}{|l|}{ Ocorrência no domicílio } \\
\hline Sim & 66,6 & 66,9 & 58,0 & \multirow[t]{2}{*}{0,0234} \\
\hline Não & 33,4 & 33,1 & 42,0 & \\
\hline \multicolumn{5}{|l|}{ Natureza da lesão } \\
\hline Contusão/entorse/luxação & 33,8 & 34,1 & 23,7 & \multirow[t]{4}{*}{0,0000} \\
\hline Corte/laceração/amputação & 35,7 & 35,6 & 37,1 & \\
\hline Fratura/trauma & 21,6 & 21,7 & 18,4 & \\
\hline Outros & 8,9 & 8,5 & 20,9 & \\
\hline \multicolumn{5}{|l|}{ Parte do corpo atingida } \\
\hline Cabeça e tronco & 52,1 & 51,7 & 64,7 & \multirow[t]{2}{*}{0,0012} \\
\hline Extremidades & 47,9 & 48,3 & 35,3 & \\
\hline \multicolumn{5}{|l|}{ Locomoção para o hospital } \\
\hline Veículo particular & 53,9 & 54,4 & 41,0 & \multirow[t]{3}{*}{0,0013} \\
\hline Assistência pré-hospitalarc & 18,6 & 18,4 & 25,1 & \\
\hline A pé/transporte coletivo/outros ${ }^{\mathrm{d}}$ & 27,5 & 27,2 & 33,9 & \\
\hline \multicolumn{5}{|l|}{ Período de atendimento } \\
\hline Diurno (07h00min-18h59min) & 56,8 & 57,0 & 52,8 & \multirow[t]{2}{*}{0,3110} \\
\hline Noturno (19h00min-06h59min) & 43,2 & 43,0 & 47,2 & \\
\hline \multicolumn{5}{|l|}{ Dia de atendimento } \\
\hline Sábado e domingo & 31,6 & 32,1 & 18,6 & \multirow[t]{2}{*}{0,0002} \\
\hline Segunda a sexta & 68,4 & 67,9 & 81,4 & \\
\hline \multicolumn{5}{|l|}{ Evolução ${ }^{\mathrm{f}}$} \\
\hline Alta & 80,5 & 80,7 & 74,2 & \multirow[t]{2}{*}{0,0492} \\
\hline Internação/transferência & 19,5 & 19,3 & 25,8 & \\
\hline
\end{tabular}

Fonte: MS, SVS, Sistema de Vigilância de Violências e Acidentes-VIVA, Inquérito 2009. a) O número de atendimentos variou devido a exclusão de registros incompletos (ignorado/em branco). b) Teste do qui-quadrado de Pearson. c) Inclui unidades do Serviço de Atendimento Móvel de Urgência (SAMU), ambulâncias, resgate. d) Inclui viatura policial e outros. e) Inclui trauma cranioencefálico, trauma dentário, politraumatismo. f) Excluído 1 caso que evoluiu ao óbito nas primeiras 24 horas de atendimento.

atingidos, em especial nos casos de violência ( $\mathrm{p}=$ $0,0012)$. A locomoção para o hospital foi mais frequente por veiculo particular, principalmente nos episódios de acidentes. As unidades de assistência pré-hospitalar foram mais utilizadas nos casos de violência ( $p=0,0013)$. Não houve diferença segundo turno de atendimento. Em relação aos dias da semana os acidentes mais frequentes nos finais de semana e as violências, nos dias de semana $(\mathrm{p}<0,001)$. A maioria dos atendimentos teve a alta como desfecho $(80,5 \%)$, e a porcentagem de internação hospitalar ou trans- ferência foi maior nos atendimentos por violência $(\mathrm{p}=0,0492)$.

Na Tabela 2, são mostradas algumas características de acidentes e violências em crianças segundo faixa etária ( 0 a 1 ano, 2 e 5 anos, 6 a 9 anos) atendidos nos serviços de urgência emergência selecionados na amostra. Os meninos foram mais acidentados em todas as faixas etárias, predominando na de 6 a 9 anos $(62,4 \%)$ ( $<<0,001)$; nos casos de violência não houve diferença segundo sexo. A raça/ cor predominante em acidentes foi não branca, predominando em 6 a 9 
$\operatorname{anos}(66,4 \% ; \mathrm{p}<0,001)$, e, sem diferença segundo faixa etária para os atendimentos por violências. As ocorrências foram mais frequentes no domicílio, predominando entre 0 a 1 ano $(86,8 \%)$ para os acidentes ( $p<0,001)$ e entre 2 a 5 anos $(73,2 \%)$ nas violências $(p<0,001)$. Dentre os acidentes, as contusões foram a lesão mais frequente em 0 a 1 ano, os cortes predominaram em 2 a 5 anos, e as fraturas em crianças entre 6 a 9 anos $(\mathrm{p}<0,001)$. Os cortes foram as lesões mais frequentes nos atendimentos por violência. Nos episódios de acidentes, cabeça e tronco foram as regiões mais atingidas em 0 a 1 ano $(67,4 \%)$ e as extremidades em crianças de 6 a 9 anos $(p<0,001)$; dentre os atendi- mentos por violência, predominaram as ocorrências na cabeça e tronco, sem diferença segundo faixa etária. Não houve associação entre meio de locomoção para o hospital e faixa etária das vítimas de acidentes, porém, o deslocamento por veículos de assistência pré-hospitalar (SAMU) foi mais frequente entre as vítimas de violência com até 1 ano de idade $(p=0,0101)$. Em todas as faixas etárias a alta foi o desfecho mais frequente $\mathrm{e}$ os eventos foram mais frequentes durante o período diurno e em dias de semana, sem identificação de diferenças significativas segundo faixa etária.

A Tabela 3 apresenta características dos atendimentos de emergência por acidentes e violên-

Tabela 2. Características dos atendimentos de emergência por acidentes e violência entre crianças segundo tipo de ocorrência. 23 capitais e Distrito Federal, Brasil, 2009.

\begin{tabular}{|c|c|c|c|c|c|c|c|c|}
\hline \multirow[b]{2}{*}{ Características } & \multicolumn{4}{|c|}{ Acidentes $^{\mathrm{a}}$} & \multicolumn{4}{|c|}{ Violência $^{a}$} \\
\hline & $\begin{array}{c}0 \text { a } 1 \\
(\mathrm{n}=1.280) \\
\%\end{array}$ & $\begin{array}{c}2 \text { a } 5 \\
(\mathrm{n}=2.923) \\
\%\end{array}$ & $\begin{array}{c}6 \text { a } 9 \\
(\mathrm{n}=2.694) \\
\%\end{array}$ & $\begin{array}{l}\text { Valor } \\
\text { de } p^{b}\end{array}$ & $\begin{array}{c}0 \text { a } 1 \\
(n=62) \\
\%\end{array}$ & $\begin{array}{c}2 \text { a } 5 \\
(\mathrm{n}=75) \\
\%\end{array}$ & $\begin{array}{c}6 \text { a } 9 \\
(\mathrm{n}=89) \\
\%\end{array}$ & $\begin{array}{l}\text { Valor } \\
\text { de } p^{b}\end{array}$ \\
\hline \multicolumn{9}{|l|}{ Sexo } \\
\hline Masculino & 53,5 & 59,2 & 62,4 & 0,0000 & 61,6 & 61,0 & 69,9 & 0,4945 \\
\hline Feminino & 46,5 & 40,8 & 37,6 & & 38,5 & 39,0 & 30,1 & \\
\hline \multicolumn{9}{|l|}{ Raça/cor da pele } \\
\hline Branca & 46,0 & 37,9 & 33,6 & 0,0000 & 31,3 & 18,5 & 18,9 & 0,1750 \\
\hline Não branca & 54,0 & 62,1 & 66,4 & & 68,7 & 81,5 & 81,1 & \\
\hline \multicolumn{9}{|l|}{ Ocorrência no domicílio } \\
\hline Sim & 86,8 & 71,8 & 52,4 & 0,0000 & 69,0 & 73,2 & 38,2 & 0,0001 \\
\hline Não & 13,2 & 28,2 & 47,6 & & 31,0 & 26,8 & 61,8 & \\
\hline \multicolumn{9}{|l|}{ Natureza da lesão } \\
\hline Contusão/entorse/luxação & 39,7 & 30,4 & 35,5 & 0,0000 & 15,8 & 24,4 & 28,5 & 0,0555 \\
\hline Corte/laceração/amputação & 26,8 & 40,1 & 35,0 & & 33,9 & 28,8 & 44,8 & \\
\hline Fratura/trauma ${ }^{e}$ & 19,1 & 21,1 & 23,4 & & 27,0 & 14,7 & 15,1 & \\
\hline Outros & 14,4 & 8,4 & 6,1 & & 23,4 & 32,1 & 11,6 & \\
\hline \multicolumn{9}{|l|}{ Parte do corpo atingida } \\
\hline Cabeça e tronco & 67,4 & 57,1 & 39,3 & 0,0000 & 63,3 & 69,8 & 62,1 & 0,6710 \\
\hline Extremidades & 32,6 & 42,9 & 60,7 & & 36,7 & 30,3 & 37,9 & \\
\hline \multicolumn{9}{|l|}{ Locomoção para o hospital } \\
\hline Veículo particular & 55,5 & 54,1 & 54,2 & 0,2906 & 38,4 & 46,1 & 38,9 & 0,0101 \\
\hline Assistência pré-hospitalar ${ }^{c}$ & 19,8 & 18,6 & 17,6 & & 42,5 & 18,9 & 18,2 & \\
\hline A pé/transporte coletivo/outros ${ }^{\mathrm{d}}$ & 24,7 & 27,4 & 28,3 & & 19,2 & 35,1 & 42,9 & \\
\hline \multicolumn{9}{|l|}{ Período de atendimento } \\
\hline Diurno (07h00min-18h59min) & 56,6 & 58,0 & 56,0 & 0,4112 & 45,6 & 59,0 & 52,9 & 0,3972 \\
\hline Noturno (19h00min-06h59min) & 43,4 & 42,0 & 44,0 & & 54,4 & 41,0 & 47,1 & \\
\hline \multicolumn{9}{|l|}{ Dia de atendimento } \\
\hline Sábado e domingo & 30,5 & 32,6 & 32,3 & 0,5006 & 20,7 & 19,1 & 16,8 & 0,8483 \\
\hline Segunda a sexta & 69,5 & 67,4 & 67,7 & & 79,4 & 80,9 & 83,2 & \\
\hline \multicolumn{9}{|l|}{ Evolução ${ }^{\mathrm{f}}$} \\
\hline Alta & 79,3 & 80,3 & 81,8 & 0,2650 & 70,0 & 69,8 & 80,5 & 0,3334 \\
\hline Internação/transferência & 20,7 & 19,7 & 18,2 & & 30,0 & 30,2 & 19,6 & \\
\hline
\end{tabular}

Fonte: MS, SVS, Sistema de Vigilância de Violências e Acidentes-VIVA, Inquérito 2009. a) O número de atendimentos variou devido a exclusão de registros incompletos (ignorado/em branco). b) Teste do qui-quadrado de Pearson. c) Inclui unidades do Serviço de Atendimento Móvel de Urgência (SAMU), ambulâncias, resgate. d) Inclui viatura policial e outros. e) Inclui trauma cranioencefálico, trauma dentário, politraumatismo. f) Excluído 1 caso que evoluiu ao óbito nas primeiras 24 horas de atendimento. 
Tabela 3. Características dos atendimentos de emergência por acidentes e violência entre crianças segundo tipo de evento e faixa etária. 23 capitais e Distrito Federal, Brasil, 2009.

\begin{tabular}{|c|c|c|c|c|c|}
\hline \multirow[b]{2}{*}{ Características } & \multirow[b]{2}{*}{$\begin{array}{c}\text { Total } \\
(\mathbf{n}) \\
\% \\
\end{array}$} & \multicolumn{3}{|c|}{ Faixa etária (anos) ${ }^{a}$} & \multirow[b]{2}{*}{$\begin{array}{l}\text { Valor } \\
\text { de } p^{b}\end{array}$} \\
\hline & & $\begin{array}{c}0 \text { a } 1 \\
(\mathbf{n}) \\
\%\end{array}$ & $\begin{array}{c}2 \text { a } 5 \\
(\mathbf{n}) \\
\% \\
\end{array}$ & $\begin{array}{c}6 \text { a } 9 \\
(\mathbf{n}) \\
\% \\
\end{array}$ & \\
\hline Tipo de evento & $(6897)$ & $(1280)$ & $(2923)$ & $(2694)$ & \\
\hline Acidente de transporte & 11,1 & 6,1 & 11,8 & 12,8 & 0,0000 \\
\hline Queda & 53,8 & 60,9 & 52,3 & 52,1 & \\
\hline Queimadura & 2,6 & 5,5 & 2,3 & 1,4 & \\
\hline Outros acidentes & 32,5 & 27,4 & 33,6 & 33,7 & \\
\hline Acidente de transporte: tipo de vítima & $(783)$ & $(73)$ & (359) & $(351)$ & \\
\hline Pedestre & 28,0 & 23,0 & 30,1 & 27,0 & 0,0000 \\
\hline Condutor & 29,7 & $7,2^{\mathrm{c}}$ & 22,8 & 41,6 & \\
\hline Passageiro & 42,3 & 69,8 & 47,1 & 31,4 & \\
\hline Acidente de transporte: meio de locomoção da vítima & $(734)$ & $(62)$ & $(341)$ & $(331)$ & \\
\hline A pé & 28,9 & 23,5 & 31,2 & 27,7 & 0,0001 \\
\hline Automóvel & 8,8 & 24,8 & 3,5 & 11,2 & \\
\hline Motocicleta & 8,8 & 12,1 & 8,0 & 9,1 & \\
\hline Bicicleta & 53,4 & 39,6 & 57,3 & 52,1 & \\
\hline Tipo de queda & $(3635)$ & $(769)$ & $(1516)$ & $(1350)$ & \\
\hline Mesmo nível & 50,1 & 34,6 & 50,2 & 58,4 & 0,0000 \\
\hline Leito/mobília & 19,6 & 36,1 & 20,9 & 9,2 & \\
\hline Escada/degrau/árvore/telhado & 15,7 & 12,0 & 15,1 & 18,4 & \\
\hline Outros níveis ${ }^{\mathrm{d}}$ & 14,6 & 17,4 & 13,8 & 14,0 & \\
\hline Tipo de queimadura & $(181)$ & $(74)$ & $(71)$ & $(36)$ & \\
\hline Fogo/chama & 16,8 & 4,7 & 19,8 & 33,8 & 0,0047 \\
\hline Substância quente & 59,2 & 63,5 & 56,3 & 55,9 & \\
\hline Outros $^{\mathrm{e}}$ & 24,1 & 31,8 & 23,8 & 10,3 & \\
\hline Outros acidentes & $(2163)$ & $(338)$ & $(920)$ & $(905)$ & \\
\hline Corpo estranho & 21,1 & 18,9 & 30,8 & 11,8 & 0,0000 \\
\hline Choque contra objeto/pessoa & 21,7 & 11,4 & 15,6 & 32,2 & \\
\hline Ferimento perfurocortante & 15,7 & 7,8 & 14,1 & 20,5 & \\
\hline Acidente com animais & 10,4 & 7,0 & 9,6 & 12,6 & \\
\hline Queda de objeto sobre pessoa & 10,2 & 13,1 & 10,4 & 8,8 & \\
\hline Outros ${ }^{f}$ & 20,8 & 41,8 & 19,6 & 14,1 & \\
\hline \multicolumn{6}{|l|}{ Tipo de violência ${ }^{g}$} \\
\hline Física & $(201)$ & $(54)$ & $(67)$ & $(80)$ & \\
\hline Sim & 72,3 & 52,5 & 69,5 & 87,4 & 0,0002 \\
\hline Não & 27,8 & 47,5 & 30,5 & 12,6 & \\
\hline Negligência & $(194)$ & $(53)$ & $(66)$ & $(75)$ & \\
\hline Sim & 34,4 & 62,4 & 42,5 & 8,7 & 0,0000 \\
\hline Nâo & 65,6 & 37,6 & 57,5 & 91,3 & \\
\hline Agressor era um familiar ${ }^{\mathrm{h}}$ & $(191)$ & $(48)$ & $(66)$ & $(77)$ & \\
\hline Sim & 50,8 & 70,1 & 61,2 & 30,4 & 0,0000 \\
\hline Não & 49,2 & 29,9 & 38,8 & 69,6 & \\
\hline
\end{tabular}

Fonte: MS, SVS, Sistema de Vigilância de Violências e Acidentes-VIVA, Inquérito 2009. a) O número de atendimentos variou devido a exclusão de registros incompletos (ignorado/em branco). b) Teste do qui-quadrado de Pearson. c) Inclui crianças de 1 ano na condição de condutoras de bicicletas, triciclos, velocípedes. d) Inclui andaime e buraco. e) Inclui objeto quente, choque elétrico e substâncias químicas. f) Inclui sufocação/engasgamento, afogamento, envenenamento/intoxicação, ferimento por arma de fogo, entorse, esmagamento, outros. g) Inclui maus-tratos e intervenção por agente público legal. Excluídos 13 casos de lesão autoprovocada. h) Refere-se somente aos casos de agressão. Inclui: pai, mãe, padrasto, madrasta, outro familiar, exceto companheiro/ex-companheiro. 
de 0 a 1 ano foram mais frequentes as quedas do leito/mobília $(36,1 \%)(p<0,001)$.

$\mathrm{O}$ terceiro evento mais frequente foi acidente de transporte $(\mathrm{AT})$, predominando em crianças de 6 a 9 anos (12,8\%). As vítimas na condição de passageiros foram as mais comuns $(42,3 \%)$, especialmente entre as crianças de 0 a 1 ano $(69,8 \%)$; os acidentes em pedestres/atropelamentos predominaram no grupo de 2 a 5 anos $(30,1 \%)$ e as vítimas na condição de condutores (bicicleta, velocípede e similares) foram mais frequentes no grupo de 6 a 9 anos $(41,6 \%)(p<0,001)$. A bicicleta (velocípedes, triciclos e similares) $(53,4 \%)$ foi o meio de locomoção da vítima mais frequente, em especial entre as crianças de 2 a 5 anos $(57,3 \%$; $p<$ $0,001)$. As queimaduras $(2,6 \%)$ foram mais frequentes no grupo de 0 a 1 ano (5,5\%), sendo as causadas por substâncias quentes as mais frequentes em todas as faixas $(59,2 \%)$. Esse tipo de queimadura predominou entre as crianças de 0 a 1 ano, enquanto as queimaduras por fogo e chama predominaram no grupo de 6 a 9 anos $(33,8 \%)$ $(\mathrm{p}<0,05)$. Dentre os outros acidentes, destacamse: queda de objeto sobre pessoa $(13,1 \%)$ no grupo de 0 a 1 ano; corpo estranho $(30,8 \%)$ em crianças de 2 a 5 anos; em crianças de 6 a 9 anos destacam-se: choque contra objetos $(32,2 \%)$, ferimentos cortantes $(20,5 \%)$ e acidentes com animais $(12,6 \%)(\mathrm{p}<0,001)$.

A agressão física foi mais frequente em crianças de 6 a 9 anos $(87,4 \%$; p < 0,001), enquanto a negligência predominou entre as crianças mais jovens $(0-1 ; 2$ a 5 anos) $(p<0,001)$. A violência sexual ocorreu em $7,1 \%$, predominando em 2 a 5 anos $(13,6 \%)$ e a violência psicológica ocorreu em $13,2 \%$, predominando em 6 a 9 anos (dados não mostrados). $\mathrm{O}$ agressor era um familiar da criança em mais da metade dos atendimentos, com porcentagem significativamente maior quando a vítima era mais jovem, como foi observado entre as crianças de 0 a 1 ano $(70,1 \%)$ e de 2 a 5 anos $(61,2 \%)(\mathrm{p}<0,001)$.

\section{Discussão}

O estudo aqui analisado mostrou que, dentre as causas externas na infância, os serviços de urgência e emergência atenderam majoritariamente crianças vítimas de acidentes, predominando os casos mais leves, os quais receberam encaminhamento de alta, com cerca de $20 \%$ dos atendimentos evoluídos para internação ou encaminhados para outros serviços. As ocorrências foram mais frequentes no domicilio e os acidentes mais co- muns foram as quedas, seguidas de outros acidentes e acidentes de transporte. As ocorrências foram mais frequentes em crianças de 2 a 5 anos, tanto os acidentes, quanto as violências. As quedas foram mais frequentes do mesmo nível entre maiores de 2 anos, em 0 a 1 ano ocorreram mais quedas de berços, cama e mobílias. Chama a atenção o fato de a bicicleta/velocípede constituir-se no meio de locomoção da vitima mais comum entre os atendimentos por acidentes de transporte, fato relacionado ao frequente uso desse veículo nas brincadeiras próprias desse grupo etário. As agressões físicas foram o tipo mais comum de violência, sendo mais frequente em 6 a 9 anos e as negligências foram mais frequentes em crianças de 2 a 5 anos. Em mais da metade dos casos o agressor foi alguém da própria família.

Os resultados aqui apresentados mostram a importância dos acidentes e violências como demanda de atenção nos serviços públicos de urgência e emergência nas capitais do país. Nas portas de entrada destes serviços são atendidos eventos de natureza e gravidade diversa, desde ocorrências de menor gravidade, que são liberadas, até aquelas que evoluem para internação. Os primeiros constituem a maior porcentagem de demanda, requerendo procedimentos que envolvem menor complexidade assistencial, porém fundamentais para a prevenção de lesões e sequelas graves 5 .

As informações sobre causas externas baseadas em informações de mortalidade e internação subestimam estes eventos na população. A OMS estima que para cada óbito, cerca de 300 casos são tratados em serviços de emergência e depois liberados ${ }^{26,27}$. A estratégia de vigilância epidemiológica baseada em dados de atendimentos de urgência e emergência é adotada em diversos países, visando identificar características das vítimas, agressores e ocorrências que não são registradas nos demais sistemas de informação, mostrando a oportunidade da implantação do VIVA no Bra$\mathrm{sil}^{24,26,27}$.

A ocorrência dos acidentes na infância tem sido descrita na literatura como relacionada a características como sexo, idade da criança, etapa de desenvolvimento neuro-psico-motor (imaturidade física e mental, inexperiência, incapacidade para prever e evitar situações de perigo, curiosidade, tendência a imitar comportamentos adultos, falta de noção corporal e de espaço, falta de coordenação motora) e características da personalidade (hiperatividade, agressividade, impulsividade e distração), além de particularidades orgânicas ou anatômicas, tais como deficiência física e/ou mental ${ }^{5,23}$. 
Estudos têm mostrado que os acidentes na infância ocorrem com mais frequência em crianças do sexo masculino, o que pode ser justificado pelos diferentes comportamentos de cada sexo e por fatores culturais, como estímulo a determinadas brincadeiras entre meninos que são mais ativas como: jogar bola, uso de bicicleta e tendência cultural em manter as meninas em casa envolvidas em brincadeiras mais tranquilas, como brincar de bonecas ${ }^{3,4,23}$.

A ocorrência de violências também predomina no sexo masculino, o que pode ser explicado pelos mesmos comportamentos culturais de maior liberdade entre meninos e maior vigilância sobre as meninas. O universo masculino desde cedo é povoado por símbolos de masculinidade, dentre eles, brincadeiras com uso de armas, que trazem a simbologia do poder, e que podem ser incorporados na sua vida, como atos de violência cotidiana, mais frequente entre homens ${ }^{28}$.

A faixa etária de maior ocorrência de acidentes foi de 2 a 5 anos, conforme dados obtidos nas edições do Inquérito VIVA em 2006 e $2007^{23}$. Outros estudos mostraram diferenças, ora apontando crianças mais velhas (7 a 12 anos) ${ }^{4}$, ora de um a três anos ${ }^{3}$. Quanto ao tipo de acidentes por faixa, os dados do Inquérito VIVA 2009 foram comparáveis com a literatura: crianças maiores sofrem mais quedas e acidentes de transporte ${ }^{13} \mathrm{e}$ as menores sofrem mais quedas de leito/mobília e outros acidentes (afogamentos, corpos estranhos, acidentes com animais, outros) $)^{3,4,23}$.

Outros estudos também apontam que o local de ocorrência mais frequente de acidentes e violências na infância é o domicílio, como aqui descrito $^{3,4,8,23}$. O fato do ambiente doméstico ser o de maior risco para acidentes se deve ao tempo de exposição, pois são crianças que passam o maior tempo no lar, mas também em função dos fatores ambientais de risco como: tapetes soltos, pisos molhados, móveis com quinas, vidros, janelas sem proteção, berços sem proteção, camas elevadas, brinquedos espalhados, brinquedos e peças pequenas que podem ser introduzidos nos orifícios anatômicos como corpo estranho, objetos pérfuro-cortantes, fogão, medicamentos e produtos de limpeza mal armazenados, animais domésticos ${ }^{3,4}$. Deve-se enfatizar a importância da supervisão contínua de adultos, pais ou responsáveis, que devem estar atentos aos riscos, e também da necessidade de descoberta das crianças, buscando protegê-las e adotando mecanismos de segurança como: proteção nas janelas, cancelas nas extremidades das escadas, protetores de tomadas, cantoneiras, tra- vas de segurança nos sanitários, eliminação de plantas venenosas e venenos em geral, local seguro no armazenamento de medicamentos, materiais de limpeza, dentre outros ${ }^{4,23}$.

O ambiente domiciliar também foi o local de maior exposição para a ocorrência de agressões e negligência, tanto por permanecerem mais tempo em seus lares, quanto por serem os familiares os agressores mais frequentes ${ }^{8}$. Dados não mostrados neste estudo apontam a importância de ocorrências em locais de prática de esporte e na escola em crianças de 6 a 9 anos. Estudos apontam que outros espaços públicos (ruas, bares, escolas e outros locais públicos) também são locais para a ocorrência de eventos violentos, em especial quando envolvem agressores e vítimas do sexo masculino e crianças mais velhas ${ }^{28}$.

As lesões por acidentes e violências atingem com mais frequência a cabeça, seguidos pelos membros superiores e inferiores. No caso de acidentes as crianças ainda não são capazes de proteger a região cefálica em caso de quedas e impactos $^{3,29}$, o que pode aumentar os riscos de lesões graves, como traumatismo craniano, que tem sido apontado como importante causa de internação e óbito ${ }^{14}$. Crianças de 0 a 1 ano, em geral, foram mais vítimas de quedas, em especial de berços e mais expostas a traumatismo cranioencefálico (TCE). Por outro lado, crianças maiores de 5 anos têm mais lesões em membros superiores e inferiores, provavelmente porque, nessa faixa etária, predominam atividades como prática de esportes, passeio com bicicleta, uso de patins, jogos de bola, entre outros ${ }^{3}$. As crianças vítimas de violência e agressões têm a cabeça mais atingida, provavelmente em função do agressor tender a golpear preferencialmente a cabeça e face, produzindo lesões mais graves ${ }^{8}$. Com relação ao tipo de lesão, predominam os ferimentos, contusões, entorses e luxações, o que revela a menor gravidade das lesões decorrentes de causas externas em crianças atendidas nos serviços de urgência e emergência, embora estes eventos produzam custos elevados aos serviços, além de afetar enormemente as famílias e as crianças, pelas suas graves consequências emocionais e físicas ${ }^{4,5,30,31}$. O desfecho mais frequente dos casos de acidentes e violências foi a alta, a internação ocorreu em maior frequência nos casos de violência/agressão $(25,8 \%)$, enquanto o óbito, constituiu-se em evento mais raro, não descrito no atual estudo.

Dentre os acidentes, as quedas correspondem à maior porcentagem dos atendimentos seguidas dos acidentes de transporte, queimaduras, corpo estranho, ferimentos por objetos cortan- 
tes, queda de objetos sobre a pessoa, envenenamento. Esses resultados são semelhantes aos que foram encontrados por outros autores ${ }^{3,4,5,29}$.

As quedas destacam-se na faixa etária pediátrica pelas características do desenvolvimento da criança, curiosidade, imaturidade e falta de coordenação motora, o que as coloca em situações de perigo. Nas crianças maiores (6 a 9 anos) agregam-se outros fatores como atividades de lazer e esportes, próprios desta faixa etária, destacandose jogos, corridas, patins e outros. Quanto à altura das quedas, predominam as do mesmo nível (própria altura), seguida de outros níveis como cama, berço, escada, degrau, árvore, telhado, outros. Conforme descrito em outros estudos, crianças de 0 e 1 ano caem mais de berços e camas ${ }^{4}$.

Os acidentes de transporte destacam-se nos atendimentos de emergência por causas externas acidentais e primeira causa de mortalidade entre crianças de um a nove anos de idade no Brasil e no mundo ${ }^{1}$. Predominam os eventos envolvendo brincadeiras com bicicletas em crianças de 2 a 9 anos, seguidos de atropelamentos por automóveis e motocicletas na mesma faixa, e em crianças de 0 a 1 ano as vítimas de ocupantes de veículo são as mais frequentes ${ }^{1}$. O que difere dos dados de mortalidade por acidentes de transporte em crianças, pela predominância de mortes por atropelamentos, seguidos de acidentes com ocupantes de veículos e, em terceiro lugar, acidentes envolvendo ciclistas. Estes dados apontam a importância das medidas como a supervisão das crianças ao andar de bicicleta, atravessar as ruas, e o estímulo ao uso da cadeirinha (dispositivo de retenção para crianças), do cinto de segurança, bem como o transporte de crianças apenas nos bancos traseiros, além da rigorosa vigilância da circulação de veículos e punição de infratores.

As queimaduras são mais frequentes em crianças menores, especialmente por substâncias quentes, como ocorre ao puxarem para si os recipientes com líquido quente. Deve-se recomendar supervisão de adultos, e limitar o acesso à cozinha ${ }^{4,13,15}$. Acidentes envolvendo corpo estranho foram mais frequentes em crianças de 2 a 5 anos, o que pode ser explicado pela imaturidade e curiosidade típicas desta faixa etária.

O tema da violência contra a criança vem ganhando visibilidade e importância nas agendas internacionais e nacionais ${ }^{1,7,24}$. A criança tem sido cada vez mais valorizada e a percepção da violência como algo natural e um direito legitimamente exercido dos pais sobre a criança tem sido desconstruído, ganhando voz e vez na sociedade. O Estatuto da Criança e do Adolescente e a organi- zação de espaços institucionais na luta contra a violência, como os conselhos tutelares (Lei n. $8.069 / 1990)^{32}$, os sistemas locais de saúde, os serviços de prevenção de violência, os Centro de Referência de Assistência Social (CRAS) têm contribuído para o aumento dos registros e da comunicação da violência, reduzindo paulatinamente a "lei do silêncio"",33.

A literatura aponta com certa frequência que membros da família podem se tornar, em determinadas circunstâncias, autores de violência ${ }^{23,34}$. Dados do Inquérito VIVA 2009 apontam esta constatação em cerca de $51 \%$ das ocorrências, predominando a violência física e a negligência. Verificou-se predomínio de violência física e negligência/abandono, um importante problema social, caracterizado pela omissão ou ato de deixar de prover as necessidades e os cuidados básicos para o desenvolvimento físico, emocional e social da pessoa - o abandono é uma forma extrema de negligência entre crianças menores de 6 anos, justamente as mais indefesas e incapazes, dependendo dos adultos, para os cuidados.

Os dados do Inquérito VIVA apontam os maus tratos físicos, ou agressões, em primeiro lugar, entre as modalidades de violência, provavelmente por serem mais graves e exigirem atendimento de saúde. Estudos conduzidos no ambiente escolar, ou a partir de notificação do Conselho Tutelar tendem a detectar outras situações e destacam a negligência como principal ocorrência ${ }^{35}$. Tal constatação pode ser explicada por serem mais perceptíveis ou valorizadas pelos educadores, frente às mudanças de comportamento das crianças.

Estudo realizado em Feira de Santana, Bahia, a partir dos registros do Conselho Tutelar, identificou a negligência como a violência mais prevalente, seguida de violência física, a violência psicológica e por último, a sexual. Em menores de um ano, registrou-se considerável ocorrência de negligência, violência física e psicológica. A violência sexual foi registrada em todas as faixas etárias, com maior prevalência acima dos 10 anos e a exploração sexual, a partir dos $14 \operatorname{anos}^{16}$. Portanto o perfil de ocorrências pode variar conforme a fonte ou local pesquisado.

O Inquérito VIVA 2009 detectou o incremento na ocorrência da violência física com o aumento da idade da vítima, o que pode ser atribuído ao desenvolvimento e crescimento das crianças, quando os responsáveis passam a realizar mais ameaças e punições corporais.

Dentre os limites do presente estudo, citam-se a utilização da estratégia de serviços sentinelas, o que não permite estimativas populacionais, e a 
própria dificuldade da coleta, em especial entre as vítimas de violência, quando os eventos tendem a ser omitidos, podendo resultar em subnotificação, bem como a dificuldade na identificação e mensuração dos casos de abusos sexuais e psicológicos em crianças, especialmente quando cometidos pelos familiares. Por outro lado, a estratégia de serviços sentinelas agrega vantagens como: melhor capacitação e sensibilização da equipe para a realização do inquérito, articulação destes serviços de urgência com a rede de proteção à vítima de violência, possibilitando ações integradas e respostas às vítimas, além de possibilitar o uso das informações para o planejamento das ações.

Os registros do Inquérito VIVA, por ser uma estratégia de vigilância de acidentes e violências em parceria com estados e municípios, têm sido utilizados no nível local para o melhor conhecimento da violência infringida contra as crianças, e com isto a atuação tem promovido a articulação entre saúde, serviços notificadores e de toda a rede de referencia, integrando ações de promoção à saúde, prevenção e controle de violência ${ }^{6}$. Essa mobilização visa a assegurar o cumprimento de princípios legalmente assegurados no Estatuto da Criança e do Adolescente ${ }^{32}$, no que se refere às políticas e programas voltados à violência social e interpessoal contra crianças e adolescentes.

\section{Colaboradores}

DC Malta, MDM Mascarenhas, RTI Bernal, APB Viegas, NNB Sá e JB Silva Junior participaram igualmente de todas as etapas de elaboração do projeto.
Na última década algumas iniciativas importantes foram realizadas visando a prevenção das causas externas, dentre eles a publicação da Política Nacional de Redução da Morbimortalidade por Acidentes e Violências (Portaria no 737/ $2001)^{36}$, a Política Nacional de Promoção da Saúde (Portaria no 687/2006) ${ }^{37}$, os instrumentos como a notificação de violência contra crianças e adolescentes na rede assistencial do Sistema Único de Saúde (Portaria no 1.968/2001) ${ }^{38}$, a Vigilância de Violências e Acidentes (VIVA), e a Rede Nacional Prevenção da Violência, Promoção da Saúde e Cultura de Paz, contando com núcleos nos estados e municípios (Portaria 936/2004) ${ }^{22,33}$. A rede de atenção integral às vítimas de violência vem se consolidando e garantindo o acesso aos serviços de saúde especializados para crianças e adolescentes, além da notificação dos casos, são realizados encaminhamentos daqueles que necessitem de atendimento específico ou acompanhamento das redes intersetoriais e sociais.

A análise destas ocorrências pode melhor direcionar as ações de promoção à saúde, orientar o desenvolvimento de medidas de intervenção, prevenção e controle desses agravos, resultando em ações educativas que envolvam pais, famílias, profissionais de saúde e gestores na busca de redução destes eventos, em sua maioria, evitáveis.

\section{Referências}

1. World Health Organization (WHO). World report on child injury prevention. Geneva: WHO; 2008.

2. Brasil. Ministério da Saúde (MS). Saúde Brasil 2010: uma análise da situação de saúde e de evidências selecionadas de impacto de ações de vigilância em saúde. Brasília: MS; 2011.

3. Martins CBG, Andrade SM. Epidemiologia dos acidentes e violências entre menores de 15 anos em município da região sul do Brasil. Rev Latino-am Enfermagem 2005; 13(4):530-537.

4. Filócomo FRF, Harada MJS, Silva CV, Pedreira MLG. Estudo dos acidentes na infância em um pronto-socorro pediátrico. Rev Latino-am Enfermagem 2002; 10(1):41-47 .

5. Martins CBG. Acidentes na infância e adolescência: uma revisão bibliográfica. Rev Bras Enferm 2006; 59(3):344-348.

6. Minayo MCS. A inclusão da violência na agenda da saúde: trajetória histórica. Cien Saude Colet 2006; 11(Supl.):1259-1267.

7. World Health Organization (WHO). Preventing child maltreatment: a guide to taking action and generating evidence. Geneva: WHO; 2006. 
8. Mascarenhas MDM, Malta DC, Silva MMA, Lima CM, Carvalho MCO, Oliveira VLA. Violência contra a criança: revelando o perfil dos atendimentos em serviços de emergência, Brasil, 2006 e 2007. Cad Saude Publica 2010; 26(2):347-357.

9. Alexandre DT, Vieira ML. Relação de apego entre crianças institucionalizadas que vivem em situação de abrigo. Psicol Estud 2004; 9(2):207-217.

10. Malta DC, Silva MAI, Mello FCM, Monteiro RA, Sardinha LMV, Crespo C, Carvalho MGO, Silva MMA, Porto DL. Bullying in Brazilian schools: results from the National School-based Health Survey (PeNSE), 2009. Cien Saude Colet 2010; 15(Supl. 2):3065-3076.

11. Westphal MF, organizador. Violência e criança. São Paulo: Edusp; 2002.

12. Oliveira BRG, Thomazine AM, Bittar DB, Santos FL, Silva LMP, Santos RLR, Silva MAI, Carvalho MGB. A violência intrafamiliar contra a criança e o adolescente: o que nos mostra a literatura nacional. REME Rev Min Enferm 2008; 12(4):547-556.

13. Martins CBG, Andrade SM. Queimaduras em crianças e adolescentes: análise da morbidade hospitalar e mortalidade. Acta Paul Enferm 2007; 20(4):464-469.

14. Koizumi MS, Mello Jorge MHP, Nóbrega LRB, Waters C. Crianças internadas por traumatismo crânio-encefálico no Brasil, 1998: causas e prevenção. Inf Epidemiol SUS 2001; 10(2):93-101.

15. Harada MJCS, Botta MLG, Kobata CM, Szauter IH, Dutra G, Dias EC. Epidemiologia em crianças hospitalizadas por acidentes. F Med (Br) 2000; 119(4):43-47.

16. Costa COM, Carvalho RC, Bárbara JFRS, Santos CAST, Gomes WA, Sousa HL. O perfil da violência contra crianças e adolescentes, segundo registros de Conselhos Tutelares: vítimas, agressores e manifestações de violência. Cien Saude Colet 2007; 12(5): 1129-1141.

17. Bazon MR. Violências contra crianças e adolescentes: análise de quatro anos de notificações feitas ao Conselho Tutelar na cidade de Ribeirão Preto, São Paulo, Brasil. Cad Saude Publica 2008; 24(2):323-332.

18. Carvalho ACR, Barros SG, Alves AC, Gurgel CA. Maustratos: estudo através da perspectiva da delegacia de proteção à criança e ao adolescente em Salvador, Bahia. Cien Saude Colet 2009; 14(2):539-546.

19. Moura ATMS, Reichenheim ME. Estamos realmente detectando violência familiar contra a criança em serviços de saúde? A experiência de um serviço público do Rio de Janeiro, Brasil. Cad Saude Publica 2005; 21(4):1124-1133.

20. Monteiro CFS, Teles DCBS, Castro KL, Vasconcelos NSV, Magalhães RLB, Deus MCBR. Violência sexual contra criança no meio intrafamiliar atendidos no SAMVVIS, Teresina, PI. Rev Bras Enferm 2008; 61(4):459-463.

21. Mascarenhas MDM, Silva MMA, Malta DC, Moura L, Gawryszewski VP, Costa VC, Souza MFM, Morais Neto OL. Atendimentos de Emergência por Acidentes na Rede de Vigilância de Violências e Acidentes - Brasil, 2006. Cien Saude Colet 2009; 14(5):1657-1668.

22. Gawryszewski VP, Silva MMA, Malta DC, Mascarenhas MDM, Costa VC, Matos SG, Moraes Neto OL, Monteiro RA, Carvalho CG, Magalhães ML. A proposta da rede de serviços sentinela como estratégia de vigilância de violências e acidentes. Cien Saude Colet 2006; 11(Supl.):1269-1278.
23. Malta DC, Mascarenhas MDM, Silva MMA, Macário EM. Perfil dos atendimentos de emergência por acidentes envolvendo crianças menores de dez anos: Brasil, 2006 a 2007. Cien Saude Colet 2009; 14(5):16691679.

24. Brasil. Ministério da Saúde (MS). Viva: vigilância de violências e acidentes, 2009. Brasília: MS; 2010.

25. Brasil. Ministério da Saúde. Conselho Nacional de Saúde. Resolução no ${ }^{\circ}$ 196/1996. Diretrizes e Normas Regulamentadoras de Pesquisas Envolvendo Seres Humanos. Diário Oficial da União 1996; out 10.

26. World Health Organization (WHO). Injury Surveillance Guidelines. Geneva: WHO; 2001.

27. World Health Organization (WHO). Injuries and violence: the facts. Geneva: WHO; 2010.

28. Souza ER. Masculinidade e violência no Brasil: contribuições para a reflexão no campo da saúde. Cien Saude Colet 2005; 10(1):59-70.

29. Baracat ECE, Paraschin K, Nogueira RJN, Reis MC, Fraga AMA, Sperotto G. Acidentes com crianças e sua evolução na região de Campinas, SP. J Pediatr 2000; 76(5):368-374.

30. Lyons RA, Delahunty AM, Kraus D, Heaven M, Cabe MM, Allen H, Nash P. Children's fractures: a population based study. Inj Prev 1999; 5(2):129-132.

31. Malta DC, Lemos MSA, Silva MMA, Rodrigues MES, Gazal-Carvalho C, Morais Neto OL. Iniciativas de vigilância e prevenção de acidentes e violências no contexto do Sistema Único de Saúde (SUS). Epidemiol Serv Saúde 2007; 16(1):45-55.

32. Brasil. Lei n. 8.069. Dispõe sobre o Estatuto da Criança e do Adolescente, e dá outras providências. Diário Oficial da União 1990; 16 jul.

33. Malta DC, Silva MMA, Mascarenhas MDM, Souza MFM, Morais Neto, Costa VC, Magalhães M, Lima CN. A vigilância de violências e acidentes no Sistema Único de Saúde: uma política em construção. Divulg Saúde Debate 2007; 39:82-92.

34. Silva MAI, Ferriani MGC. Domestic violence: from the visible to the invisible. Rev Latino-am Enfermagem 2007; 15(2):275-281.

35. Faleiros JM, Matias ASA, Bazon MR. Violência contra crianças na cidade de Ribeirão Preto, São Paulo, Brasil: a prevalência dos maus-tratos calculada com base em informações do setor educacional. Cad Saude Publica 2009; 25(2):337-348.

36. Brasil. Portaria no 737/2001 de 16 de maio de 2001. Política Nacional de Redução da Morbimortalidade por Acidentes e Violências. Diário Oficial da União 2001; 18 maio.

37. Brasil. Portaria no 687/2006 de 30 de março de 2006 Aprova a Política de Promoção da Saúde. Diário Oficial da União 2006; 31 mar.

38. Brasil. Portaria no $1.968 / 2001$ de 25 de outubro de 2001. Dispõe sobre a notificação, às autoridades competentes, de casos de suspeita ou de confirmação de maus-tratos contra crianças e adolescentes atendidos nas entidades do Sistema Único de Saúde. Diário Oficial da União 2001; 26 out.

Artigo apresentado em 10/06/2012

Aprovado em 04/07/2012

Versão final apresentada em 14/07/2012 